\title{
Estratégias nutricionais para aumentar as propriedades nutracêuticas do leite: concentrações de enterolactona e ácido linoleico conjugado
}

\author{
Edjane Pereira SILVA ${ }^{1 *}$, Caren Paludo GHEDINI², Mariane Moreno FERRO ${ }^{3}$, \\ Juliana Marques FREIRE 3 , Jocely Gomes de SOUZA4 ${ }^{4}$, Rayanne Viana COSTA ${ }^{5}$, \\ Daiane Caroline de MOURA ${ }^{6}$
}

\author{
${ }^{1}$ Programa de Pós-Graduação em Ciência Animal Universidade Federal do Mato Grosso, Cuiabá, MT, Brasil. \\ ${ }^{2}$ University of New Hampshire, UNH, USA. \\ ${ }_{3}^{3}$ Universidade Federal de Mato Grosso, Cuiabá, MT, Brasil. \\ ${ }^{4}$ Bolsista PNPD, Universidade Federal do Ceará, Fortaleza, CE, Brasil. \\ 5Programa de Pós-Graduação em Zootecnia, Universidade Estadual Paulista, Jaboticabal, SP, Brasil. \\ ${ }^{6}$ Dairy Cattle Research Lab., Federal University of Mato Grosso, Sinop, MT, Brazil. \\ *E-mail: edjanezootecnista16@gmail.com \\ (ORCID: 0000-0002-2216-5338; 0000-0001-8532-4087; 0000-0001-6385-4618; 0000-0002-1820-578X; \\ 0000-0001-6967-161X; 0000-0002-7867-377X; 0000-0002-8276-2089)
}

Recebido em 10/03/2021; Aceito em 03/11/2021; Publicado em 17/11/2021.

\begin{abstract}
RESUMO: Objetivou-se descrever estratégias nutricionais para aumentar as propriedades nutracêuticas do leite, incluindo principalmente estratégias para o aumento nas concentrações de enterolactona (EL) e ácido linoleico conjugado (CLA). Os compostos EL e CLA, ambos produzidos endogenamente a partir de componentes da dieta, são compostos bioativos presente no leite e têm sido apontados como compostos nutracêuticos, capazes de melhorar a saúde humana através da prevenção e tratamento de doenças. Estratégias nutricionais aplicadas na alimentação de vacas leiteiras possibilitam o aumento da concentração destes compostos no leite, tornando possível a produção de leite com maior potencial de beneficiamento a saúde humana. A inclusão de fontes de lignanas vegetais, como por exemplo, o farelo de linhaça e a inclusão de fontes de sacarose na dieta de vacas leiteiras possibilitam aumentar a concentração de EL no leite. Da mesma forma, o fornecimento de fontes ricas de ácidos graxos polinsaturados, como por exemplo, os óleos vegetais, possibilita o aumento da concentração de CLA no leite. A temática da nutrição animal voltada para o aumento das propriedades nutracêuticas do leite, apesar de estar iniciando, apresenta grande perspectiva, e é uma ferramenta valiosa para promoção da associação do leite com benefícios a saúde humana.
\end{abstract}

Palavras-chave: nutracêutico; compostos bioativos; lignanas; vacas de leite; benefícios do leite; redução do risco de doenças.

\section{Nutritional strategies to improve nutraceutical proprieties of milk: improvements on milk enterolactone and conjugated linoleic acid}

\begin{abstract}
This study aimed to describe nutritional strategies to increase milk nutraceutical properties, including mainly strategies to increase the concentrations of enterolactone (EL) and conjugated linoleic acid (CLA). Enterolactone and CLA are endogenously produced from dietary components and have been identified as nutraceutical compounds with the potential of improving human health through the prevention and treatment of diseases. The concentration of these compounds in milk can be modulated through nutritional strategies which enable to produce milk with greater potential for improving human health. The inclusion of vegetable lignans sources, such as flaxseed meal and the inclusion of sucrose sources in the diet of dairy cows increase the concentration of EL in milk. Feeding sources of polyunsaturated fatty acids, such as vegetable oils, results in increased concentration of CLA in milk. The application of animal nutrition to increase nutraceutical properties of milk is a valuable tool for promoting the association of milk with human health benefits and is of great interest.
\end{abstract}

Keywords: nutraceutical proprieties; bioactive compounds; lignans; dairy cows; health benefits of milk; disease risk reduction.

\section{INTRODUÇÃO}

Os alimentos de origem animal, incluindo o leite e a carne, contribuem de forma vital para a nutrição da população global, pois, são excelentes fontes de macro e micronutrientes. Os produtos pecuários representam 18\% das calorias globais, 34\% do consumo global de proteínas e fornecem micronutrientes essenciais, como vitamina B12, ferro e cálcio (FAO, 2017). Apesar do papel primordial dos alimentos de origem animal na nutrição humana, estes alimentos estão sendo cada vez mais questionados quanto seus malefícios para saúde humana e para o meio ambiente e, dietas que excluem parcial ou totalmente alimentos de origem animal estão em ascendência na sociedade contemporânea 
(JACOBS et al., 2009; LEITZMANN, 2017). Uma alternativa para incentivar o consumo de alimentos de origem animal é aumentar suas propriedades nutracêuticas, desta forma, aumentar os benefícios destes alimentos para a saúde humana.

A evolução da ciência da nutrição permitiu que, na atualidade, muito mais se saiba sobre a ação de cada nutriente no organismo e, além disso, vem demonstrando que algumas substâncias normalmente presentes nos alimentos, denominadas compostos bioativos, mas não consideradas como nutrientes, podem ser importantes, principalmente para redução do risco de doenças em humanos (ESPIN et al., 2007).

Os compostos bioativos encontrados nos alimentos podem ser classificados em: probióticos e prebióticos, alimentos sulfurados e nitrogenados, pigmentos e vitaminas, compostos fenólicos, ácidos graxos poliinsaturados e fibras (MORAES; COLLA, 2006). Os alimentos com propriedades nutracêuticas, também chamados de alimentos funcionais, são caracterizados por possuírem compostos bioativos que oferecem benefícios à saúde humana, além do valor nutritivo inerente à sua composição química, podendo desempenhar um papel potencialmente benéfico na redução do risco de doenças crônicas degenerativas, como câncer e diabetes, dentre outras (BRASIL, 2009).

Estudos têm sido conduzidos com o objetivo de aumentar a quantidade de compostos bioativos em alimentos de origem animal, incluindo aqueles advindos de animais ruminantes como a carne e o leite (PETIT; GAGNON, 2008; PETIT et al., 2009; BAARS et al., 2012; MARINO et al., 2014; BRITO et al., 2015; GHEDINI et al., 2017) e assim, aumentar o benefício destes alimentos para a saúde humana.

O leite e os produtos lácteos que merecem destaque na alimentação humana, pois são alimentos de grande valor nutricional e, portanto, contribuem para uma alimentação saudável e equilibrada (FAO, 2013; MUNIZ et al., 2013). Pesquisas têm demonstrado que é possível aumentar as propriedades nutracêuticas do leite através da manipulação da alimentação e nutrição de vacas leiteiras (PETIT; GAGNON, 2009; BRITO et al., 2015; LIMA et al., 2016; GHEDINI et al., 2017). Alimentos com propriedades nutracêuticas têm sido adicionados à dieta das vacas com o intuito de que os compostos bioativos destes alimentos sejam transferidos para o leite.

Como exemplo, podemos citar a EL e o CLA, ambos compostos bioativos presente no leite capazes de promover benefícios para a saúde humana. A inclusão de fontes de lignanas vegetais como por exemplo, o farelo de linhaça na dieta de vacas leiteiras (PETIT; GAGNON 2009; BRITO et al., 2015), bem como a inclusão de fontes de sacarose (GHEDINI et al., 2017) possibilitam aumentar a concentração de enterolactona no leite. $\mathrm{O}$ fornecimento de fontes ricas de ácidos graxos poliinsaturados, como por exemplo os óleos vegetais, possibilitam o aumento da concentração de CLA no leite (MAIA et al., 2006; RIBEIRO et al., 2014). Estes estudos têm demonstrado que a concentração de compostos bioativos no leite, que reflete o potencial nutracêutico do leite, pode ser modulada por alterações na dieta das vacas que possibilitam a transferência de compostos bioativos para o leite.

Desta forma, estes estudos mostram que a nutrição animal pode ser usada como uma ferramenta para aumentar o potencial benéfico do leite à saúde humana. Apesar dos esforços realizados até agora, a nutrição e a alimentação animal priorizam muito pouco o aumento das propriedades nutracêuticas dos alimentos de origem animal incluindo o leite. Neste sentido, revisar e entender as estratégias nutricionais que têm sido desenvolvidas e que possibilitam potencializar as propriedades nutracêuticas do leite é de grande importância.

Destarte objetivou-se descrever estratégias nutricionais para aumentar as propriedades nutracêuticas do leite, focando principalmente nas estratégias para aumentar a concentração de EL e CLA no leite, compostos bioativos com efeito benéfico à saúde humana.

\section{REVISÃO DE LITERATURA}

\subsection{Importância da ingestão de leite}

O leite é um alimento nutritivo, principal fonte de cálcio dos grupos da pirâmide, sendo essencial para o crescimento e manutenção da saúde (PHILIPPI et al., 1999). O leite na alimentação diária é indiscutível devido á riqueza em nutrientes e, ainda, por proporcionar um conjunto equilibrado e abrangente de benefícios para a saúde humana, promovendo o crescimento, contribuindo para formação e renovação do tecido ósseo, regulando o sistema nervoso e aumentando a resistência a doenças infecciosas (GOMES et al., 2008)

O consumo de leite é importante nos diversos períodos da vida. $\mathrm{Na}$ infância, participa no desenvolvimento e formação do organismo fornecendo proteína, sais minerais e gordura na adolescência, o leite fornece condições para o rápido crescimento com ótima constituição muscular, óssea e endócrina e, para pessoas idosas, é fonte principal de cálcio sendo fundamental na manutenção da integridade dos ossos (MACHADO et al., 2003).

Vários estudos vêm apontando benefícios do consumo de leite. Pesquisas realizadas por Martins et al. (2007); Micinskia et al. (2012) demostraram que o consumo de leite reduz os níveis de colesterol LDL (lipoproteína da baixa densidade), isso ocorre, devido ao consumo de ácido graxo, considerado hipocolesterémico, e ajuda a diminuir a viscosidade do sangue e da pressão sanguínea, assim como atua na regulação da secreção de insulina, e da atividade hormonal, atenua as reações alérgicas, melhora a resposta imunitária.

Estudos realizados por Massey (2001) verificou que o consumo de produtos lácteos pode estar relacionado com redução da pressão arterial e de acidente vascular cerebral, por conter quantidades significativas de cálcio, magnésio e potássio.

Sonesttedt et al. (2011) e Huth; Park (2012), constataram que o consumo de três ou mais porções diárias de produtos lácteos diminuem os riscos pressão arterial alta. Além de reduzir a ocorrência de síndrome de resistência à insulina nos indivíduos com sobrepeso e obesos, pode também reduzir a ocorrência de diabetes tipo 2 e doenças cardiovasculares (PEREIRA et al., 2002).

\subsection{Propriedades do leite}

O Nutrient Rich Foods (NRF), classifica os alimentos com base em sua composição nutricional, o leite pode ser considerado um alimento de elevada densidade nutritiva, uma vez que apresenta grande concentração de nutrientes em relação ao seu teor calórico (USDA; USDHHS, 2010).

O leite contém todos os nutrientes necessários para a sobrevivência e o crescimento inicial dos mamíferos 
neonatos. Os nutrientes do leite incluem fontes de energia (lipídeos e carboidratos), proteínas para o fornecimento de aminoácidos, vitaminas, minerais (cinzas) para eletrólitos e água (FRANDSON et al., 2011). Estes nutrientes no leite variam de acordo com a espécies animal (Tabela 1).

Os teores de constituintes podem variar também entre leites provenientes da mesma fonte, de acordo com diversos fatores como por exemplo raça, dieta, idade entre outros (CAPUANO et al., 2014).

Tabela 1. Constituintes de leite em gramas por litro de acordo com cada espécie.

Table 1. Constituents of milk in grams per liter according to each species.

\begin{tabular}{lccccc}
\hline Espécie & Gordura & Proteína & Lactose & Min. T. & Ca \\
\hline Ovelha & 70 & 60 & 40 & 8,0 & 1,9 \\
Vaca & 38 & 37 & 48 & 7,0 & 1,3 \\
Cabra & 40 & 35 & 45 & 7,8 & 1,2 \\
\hline
\end{tabular}

Min. T. (minerais totais), Ca (cálcio). Fonte: adaptado de Ordónez et al. (2005).

Min. T. (total minerals), Ca (calcium). Source: adapted from Ordónez et al. (2005).

\subsubsection{Gordura do leite}

A fração lipídica do leite é composta por triacilgliceróis (98\%), diacilglicerol $(2 \%)$, colesterol $(<0,5 \%)$, fosfolipídios $(\sim 1 \%)$ e ácidos graxos livres $(0,1 \%)$. Dentre os ácidos graxos (AG) presentes no leite, $70 \%$ são saturados, com destaque para o palmítico (C16), mirístico, esteárico (C18) e para os AG de cadeia curta, com destaque ao butírico e capróico. Os insaturados compreendem $30 \%$, com maior representatividade de ácido oleico, linoléico e $\alpha$-linolênico (FAO, 2013).

No entanto, embora a grande contribuição do consumo de leite com o aumento de AG saturados na dieta humana, estudos vem demonstrando que o consumo da gordura do leite está inversamente relacionado com doenças cardíacas e riscos de obesidade (CHOWDHURY et al., 2014; GERMAN et al., 2009; KRATZ et al., 2013; PATTERSON et al., 2013)

O leite de vaca possui naturalmente e que nas quantidades de AG trans, oriundas de processos metabólicos do intestino dos ruminantes. Dentre estas, destaca-se o ácido linoleico conjugado (CLA), que vem sendo associado a benefícios à saúde humana, tais como melhora da condição cardiovascular, do sistema imunológico, além de potencial efeito anticancerígeno e hipolipomiante (Benjamin e Spener, 2009). Estudos indicam que os lácteos compreendem $70 \%$ da quantidade de CLA consumido diariamente (FAO, 2013).

\subsubsection{Carboidratos do leite}

O principal carboidrato presente no leite é a lactose, sendo de 40 a 50 gramas por litro, ou de 8 a 10 gramas por copo $(200 \mathrm{ml})$. Fisiologicamente, este açúcar contribui para o aumento da absorção intestinal de cálcio, magnésio e fósforo presentes no leite, assim como na utilização de vitamina D pelo organismo (FAO, 2013).

A lactose é um dissacarídeo que contém partes iguais de glicose e galactose. É exclusiva da glândula mamária, mas pequenas quantidades são encontradas no plasma durante a lactação. O principal precursor da lactose no sangue é a glicose, o proprionato também é um precursor, pela via da glicose (REECE, 1996)

\subsubsection{Proteínas do leite}

As principais proteínas do leite sintetizadas para exportação nas células epiteliais mamárias bovinas são as proteínas da classe caseína ( $\alpha$ s -, $\beta$ - e k-caseína), que constituem a maior parte das proteínas do leite e $\beta$ lactoglobulina e a $\alpha$-lactoalbumina (REECE, 1996; REECE, 2006). Também estão presentes as albuminas e as imunoglobulinas (FRANDSON et al., 2011).

\subsubsection{Minerais do leite}

Os principais minerais presentes no leite da vaca são: cálcio $(0,12 \%)$, fósforo $(0,10 \%)$, sódio $(0,05 \%)$, potássio $(0,15 \%)$ e cloro $(0,11 \%)$. Outros minerais são encontrados em pequenas quantidades incluindo magnésio, enxofre, cobre, cobalto, ferro, iodo e zinco (REECE, 2006).

\subsubsection{Vitaminas}

As vitaminas B e K são sintetizadas pelos ruminantes, e sua concentração no leite não é influenciada pela dieta. As vitaminas $\mathrm{A}, \mathrm{D}$ e $\mathrm{E}$ não são sintetizadas no rúmen, sendo sua presença dependente da dieta. A concentração de vitamina $C$ no leite não é grandemente influenciada pela dieta (REECE, 1996)

\subsection{Estratégias nutricionais para aumentar o potencial nutracêutico do leite}

O leite é considerado um alimento completo por possuir a maior parte dos nutrientes essenciais. Além dos componentes tradicionais (gordura, carboidratos, proteína, lipídeos, minerais e vitaminas) pesquisas tem demonstrado que o leite é uma ótima fonte de biopeptideos e outros compostos bioativos que são necessários para a manutenção do organismo e para a prevenção de doenças. Por possuir estes componentes, o leite é considerado um alimento funcional, ou seja, alimento com propriedades nutracêuticas. Por definição, alimentos com propriedades nutracêuticas são aqueles que conferem benefícios a saúde, incluindo a prevenção e/ou o tratamento de doenças (MAZZA, 1998).

O termo nutracêutico foi introduzido no final da década de 80 por Stephen De Felice, M.D., fundador da Foundation for Innovation in Medicine. Alimentos nutracêuticos são também chamados de alimentos funcionais uma vez que além de fornecem nutrientes são capazes de benefíciar a saúde humana (MAZZA, 1998; SINGH; SACHA, 2011).

Neste sentido, pesquisas foram conduzidas com o objetivo de aumentar o potencial nutracêutico do leite. Pesquisas investigando estratégias para o aumento do CLA e EL têm sido desenvolvidas e demonstram que a nutrição animal pode ser utilizada como uma ferramenta para aumentar o potencial benéfico do leite a saúde humana.

\subsubsection{Aumento na concentração de enterolactona no leite}

As enterolignanas, enterolactona (EL) e enterodiol (ED), compostos bioativos sintetizados por mamíferos apartir de ligananas vegetais, exercem diversas atividades biológicas, incluindo: propriedades antioxidantes, antitumorais e fracamente ligadas ao estrogênio. Atualmente, existe um grande interesse em promover a inclusão de alimentos ricos em lignanas na dieta de humanos devido aos efeitos benéfícos das enterolignanas a saúde humana, incluindo principalmente a prevenção de doenças cardiovasculares, hipercolesterolemia, câncer de mama e próstata, sintomas da menopausa e osteoporose (MURKIES et al. al., 1998; ADLERCREUTZ, 2002).

As lignanas presentes em plantas,são compostos fenólicos classificados como fitroestrógenos. Os 
fitoestrógenos são um grupo diversificado de compostos encontrados naturalmente em muitas plantas comestíveis e suas sementes que possuem um grupo fenólico compartilhado com esteróides estrogênicos e função biológica similar ao estrogênio (WANG et al., 2002). Em mamíferos, as lignanas vegetais são convertidas através da ação de microrganismos gastrointestinais em enterolignanas, EL e ED. Por cerca de duas décadas, apenas as lignanas seicoisolariciresinol diglucosídeo (SDG) e Matairesinol (MAT) eram conhecidas como sendo precursores de enterolignanas, mas recentemente têm sido mostrados que pinoresinol (PINO) e lariciresinol (LARI) são eficientemente convertidos em enterolactona (MILDER et al., 2007). A estrutura química das principais lignanas vegetais e das enterolignanas estão representadas na Figura 1.<smiles>COc1cc(CC(CO)C(CO)Cc2ccc(O)c(OC)c2)ccc1O</smiles>

$\operatorname{Seco}(2 R, 3 R)$<smiles>COCC(c1ccc(O)c(OC)c1)C1CCOC1c1ccc(O)c(OC)c1</smiles>

Pin (3R, 3aR, 6S, 6aR)<smiles>COc1cc(CC2COC(=O)C2Cc2ccc(O)c(OC)c2)ccc1O</smiles>

Mat $(3 R, 4 R)$<smiles>COc1cc(CC2COC(c3ccc(O)c(OC)c3)C2CO)ccc1O</smiles>

Lari $(2 S, 3 R, 4 R)$<smiles>COc1ccc(CC2COC(=O)C2Cc2ccc(OC)c(OC)c2)cc1OC</smiles>

$\operatorname{Arg}(2 R, 3 R)$<smiles>c1cc2c(cc1C1OC[C@@H]3[C@H](c4ccc5c(c4)OCO5)CO[C@@H]13)OCO2</smiles>

Ses (1S, 3aR, 4S, 6aR)<smiles>COc1cc(C2OCC3C(c4cc(OC)c(O)c(OC)c4)OCC23)cc(OC)c1O</smiles>

Syr (1S, 4S, 5S)

$\operatorname{Med}(3 S, 3 a R, 6 a R)$<smiles>COc1ccc(C(O)C2COC(=O)C2Cc2ccc(O)c(O)c2)cc1</smiles>

7 Hydroxymatareisinol (3R, 4R)<smiles>OC[C@@H](Cc1cccc(O)c1)[C@H](CO)Cc1cccc(O)c1</smiles><smiles>O=C1OCC(Cc2cccc(O)c2)C1Cc1cccc(O)c1</smiles>

ENL $(3 R, 4 R)$

Figura 1. Lignanas vegetais: secoisolariciresinol (Seco), mataresinol (Mat), pinoresinol (Pin), mediorresinol (Med), lariciresinol (Lari), syringaresinol (Syr), artigenina (Arg), Sesamin (Ses). Lignanas de mamíferos: enterodiol (END) e enterolactona (ENL). Fonte: adaptado de Landete (2012).

Figure 1. Vegetable lignans: secaisolariciresinol (Seco), mataresinol (Mat), pinoresinol (Pin), mediorresinol (Med), lariciresinol (Lari), syringaresinol (Syr), artigenin (Arg), Sesamin (Ses). Mammalian lignans: enterodiol (END) and enterolactone (ENL). Source: adapted from Landete (2012).

A linhaça (Linum usitatissimum) é a principal fonte de lignanas vegetais. Nas plantas, as lignanas são encontradas associadas a camada externa das fibras (THOMPSON et al.,1991; ADLERCREUTZ; MAZUR, 1997), assim, o farelo de linhaça apresenta maior concentração de lignanas comparado ao grão de linhaça.

Secoisolariciresinol diglucosido (SDG) representa 95\% das lignanans encontradas na linhaça. Em mamífero não ruminantes, incluindo humanos, a conversão da lignana SDG em enterolignanas, realizada por microorganismos do trato gastro intestinal, pode ser descrita por quatro tipos de reações catalíticas: O-deglicolisação, O-demetilação, desidrogenação e desidroxilação, conforme ilustrado na Figura 2.

Em ruminantes, o metabolismo das lignanas não está completamente elucidado. Sabe-se que as lignanas vegetais são convertidas a EL e ED pela microbiota ruminal e fecal 
(CORTES et al., 2008). Estudos recentes demostraram que o metabolismo de lignanas em ruminantes ocorre principalmente no rúmen, onde as lignanas vegetais são convertidas a enterolignanas pela ação de bactérias ruminais (CORTES et al., 2008; GAGNON et al., 2009a).

O estudo realizado por Gagnon et al. (2009a) foi o primeiro estudo in vivo que investigou o papel dos microorganismos rumimais no metabolismo de lignanas da linhaça em vacas leiteiras. Neste estudo, vacas Holandesas portadoras de cânula ruminal receberam os seguintes tratamentos: (1) óleo e casca de linhaça administrados no rúmen e infusão abomasal de água; (2) óleo e casca de linhaça administrados no abomaso; (3) óleo de linhaça infundido no abomaso e casca de linhaça colocados no rúmen e (4) óleo de linhaça colocado no rúmen e casca de linhaça administrada no abomaso. A concentrações de EL no leite e urina foram respectivamente, 12 e 16 vezes maiores com a administração da casca de linhaça no rúmen. De forma similar, a concentração plasmática de EL foi três vezes maior em vacas que receberam casca de linhaça no rúmen. Estes resultados demonstram que os microorganismos ruminais desempenham papel central no metabolismo de lignans em vacas leiteiras.

Em ruminantes, o metabolismo das lignanas não está completamente elucidado. Sabe-se que as lignanas vegetais são convertidas a EL e ED pela microbiota ruminal e fecal (CORTES et al., 2008). Estudos recentes demostraram que o metabolismo de lignanas em ruminantes ocorre principalmente no rúmen, onde as lignanas vegetais são convertidas a enterolignanas pela ação de bactérias ruminais (CORTES et al., 2008; GAGNON et al., 2009a).
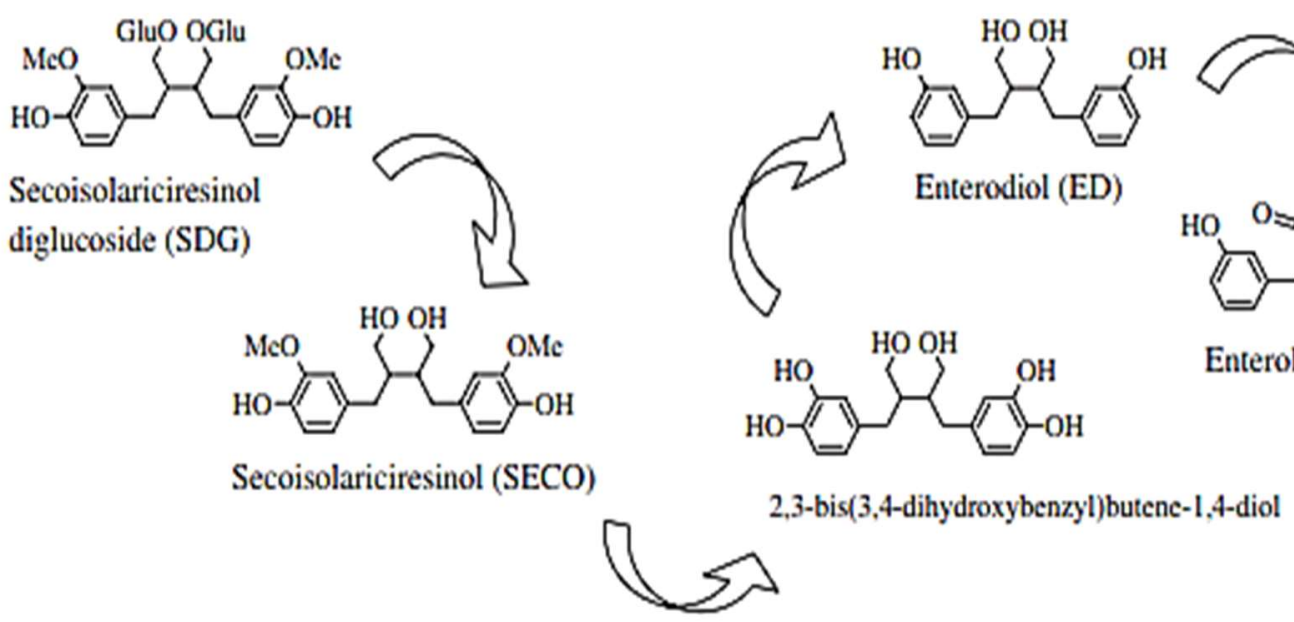

Figura 2. Estrutura química do diglucósido secoisolariciresinol e seus metabólitos bacterianos. Fonte: Clavel et al (2006). Figure 2. Chemical structure of dryisolariciresinol diglucoside and its bacterial metabolites. Source: Clavel et al (2006).

Apesar da importância dos microrganismos ruminais no metabolismo de lignanas em animais ruminantes, apenas um pequeno número de estudos tem investigado o metabolismo de lignans no rúmen e como alterações na dieta podem afetar este processo. Recentemente, Schogor et al. (2014) estudaram o metabolismo de lignanas utilizando culturas puras de bactériais ruminais incubadas com SDG. Foi reportado que 11 espécies bacterianas ruminais, principalmente Prevotella spp são capazes de converter SDG a SECO, um intermediário formado no metabolismo de SDG a EL no rúmen. Estes resultados sugerem que Prevotella spp. possivelmente seja o gênero de microorganismo ruminais que desempenha papel central no metabolimo de lignanas em vacas leiteiras (SCHOGOR et al., 2014).

A enterolactone tem sido identificada como o principal metabólico de lignanas presente no fluído ruminal, urina, plasma e leite de vacas leiteiras (PETIT; GAGNON, 2009; GAGNON et al., 2009a; BRITO et al., 2015). Saarinen et al. (2002) reportaram que a concentração de EL na urina de ratos alimentados com EL pura é cinco vezes maior do que a concentração de EL na urina de ratos alimentados com lignanas vegetais. Esta descoberta mostra que antes de serem absorvidas, as lignanas vegetais precisam ser convertidas a enterolignanas pelos microrganismos do colón, enquanto que a EL desconjugada é passivamente absorvida no intestino de mamíferos.
A concentração de EL no leite de vacas leiteiras pode ser modulada através de estratégias alimentares e o leite com uma maior concentração de EL pode possivelmente ser utilizado como uma fonte de EL para humanos (PETIT, GAGNON, 2009; BRITO et al., 2015). Humanos dependem da ação de microrganismos intestinais para converter as lignanas vegetais em enterolignanas (THOMPSON et al., 1991). Desta forma, o consumo de leite com maior concentração de EL é possivelmente mais eficiente em disponibilizar EL no organismo humano, do que o consumo de plantas fontes de lignanas vegetais, incluindo a linhaça.

A alimentação de vacas leiteiras com fontes ricas em SDG, como por exemplo casca e farelo de linhaça, tem resultado em aumento na concentração de EL no leite. Petit et al. (2009b), avaliaram o efeito da alimentação com farelo e grão inteiro de linhaça (ambos ofertados a 10\% da MS da dieta) na concentração de ED e EL no leite de vacas Holandesas. Enterodiol não foi detectado no leite, possivelmente devido ao fato de que durante o metabolismo das lignanas a maior parte do ED é convertida a EL. A concentração de EL no leite foi maior em vacas recebendo o farelo de linhaça quando comparada a vacas que receberam o grão inteiro de linhaça. A alimentação com farelo de linhaça resulta em maior consumo de SDG, visto que, como já mensionado, as lignanas são associadas a parte fibrosa das plantas, e maior consumo de SDG explica o maior teor de 
EL no leite de vacas alimentadas com farelo de linhaça. Petit e Gagnon (2009b) alimentaram vacas Holandesas com níveis crescentes de farelo de linhaça: 0, 5, 10 and 15\% da MS e reportaram aumento linear na concentração de EL no leite (Figura 3).

Da mesma forma, Petit; Gagnon (2011) obtiveram aumento linear na concentração de EL no leite quando níveis crescentes de casca de linhaça $(0,5,10,15,20 \%$ da MS) foram adicionados na dieta de vacas Holandesas (Figura 4).

Em estudo subsequente, Lima et al. (2016) investigaram o efeito da inclusão do farelo de linhaça na dieta e da infusão abomasal de óleo de linhaça e sua relação na concentração de EL no leite de vacas Holandesas portadoras de canula ruminal. As vacas receberam quatro tratamentos: (1) dieta controle, sem farelo de linhaça (CON); (2) dieta contendo 12,4\% de farelo de linhaça na MS; (3) dieta sem farelo de linhaça e infusão de $250 \mathrm{~g}$ de óleo de linhaça no abomaso; e (4) dieta contendo $12.4 \%$ de farelo de linhaça na MS e infusão de $250 \mathrm{~g}$ de óleo de linhaça no abomaso. A adição de farelo de linhaça na dieta aumentou a concentração de EL do leite. A concentração de EL no leite foi de $2.11 \mathrm{mg} / \mathrm{d}$ e $2.61 \mathrm{mg} / \mathrm{d}$ em vacas que receberam os tratamentos 2 e 4, respectivamente (LIMA et al., 2016).

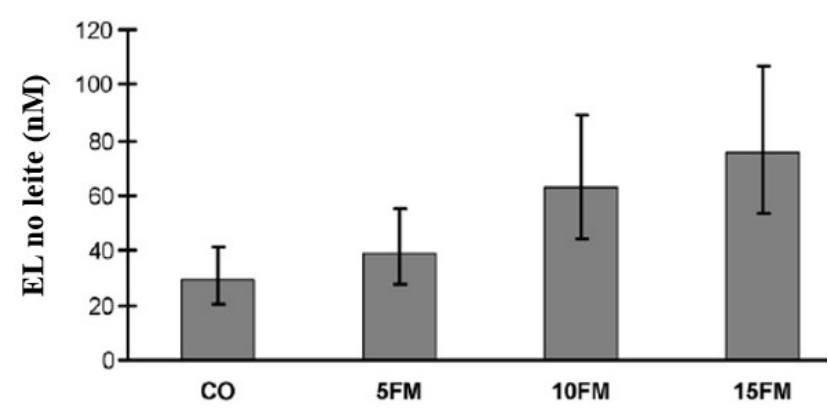

Figura 3. Concentração de enterolactona (nM) no leite de vacas alimentadas com níveis crescentes de farelo de linhaça (CO) ou 50 (5FM), 100 (10FM) e 150 (15FM) g / Kg na matéria seca. As barras verticais representam as médias com intervalos de confiança. Fonte: Petit; Gagnon (2009).

Figure 3. Concentration of enterolactone (nM) in the milk of cows fed with increasing levels of flaxseed bran (CO) or 50 (5FM), 100 $(10 \mathrm{FM})$ and $150(15 \mathrm{FM}) \mathrm{g} / \mathrm{kg}$ in dry matter. The vertical bars represent the averages with confidence intervals. Source: Petit; Gagnon (2009).

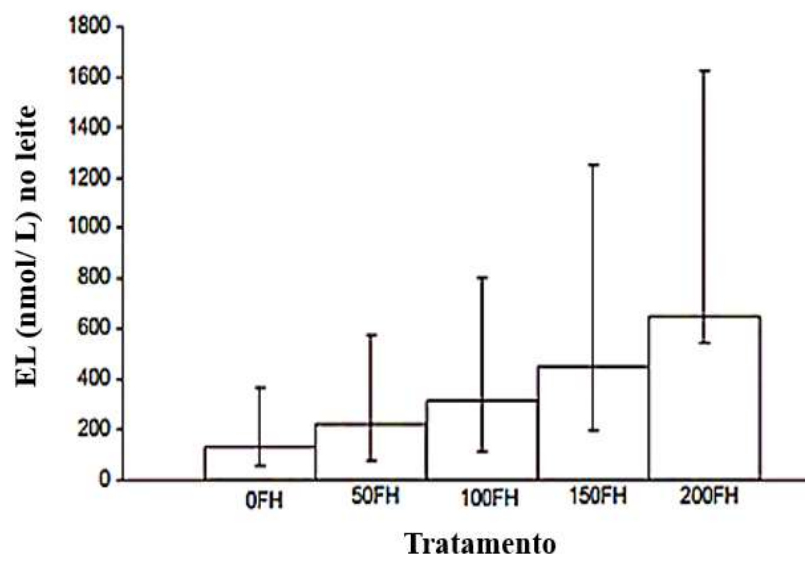

Figura 4. Concentração (nmol / l) de enterolactona (EL) no leite de vacas alimentadas com $0,50,100,15$ ou $200 \mathrm{~g} / \mathrm{kg}$ de casca de linhaça na matéria seca. Fonte: Petit; Gagnon (2011).

Figure 4. Concentration (nmol / l) of enterolactone (EL) in the milk of cows fed with $0,50,100,15$ or $200 \mathrm{~g} / \mathrm{kg}$ of linseed skin in the dry matter. Source: Petit; Gagnon (2011).
Mais recentemente, em um estudo conduzido nos Estados Unidos com vacas Jersey, foi demonstrado que a concentração de enterolactona no leite de vacas leiteiras alimentadas com dietas a base de farelo de linhaça pode ser modulada pela fonte de carboidratos não estruturais (CNS) presente na dieta. Este estudo desmonstrou que a alimentação com melaço líquido, fonte de sacarose, resulta em maior concentração de EL do que a alimentação com farelo de milho, fonte de amido, quando a dieta de vacas leiteiras tem o farelo de linhaça como base proteica. As vacas foram alimentadas com dietas a base de feno e receberam quatro diferentes concentrados: (1) milho mais uma mistura de fontes proteícas contendo farelo de soja e farelo de girassol; (2) milho mais farelo de linhaça; (3) melaço líquido mais mistura de fontes proteícas contendo farelo de soja e farelo de girassol e (4) melaço líquido mais farelo de linhaça. Vacas que receberam o farelo de linhaça apresentaram maior concentração de EL no leite. Adicionalmente, foi reportado que vacas recebendo farelo de linhaça e melaço líquido produziram leite com concentrações maiores maior de EL do que vacas alimentadas com farelo de linhaça e farelo de milho. Estes resultados sugerem que a sucrose é possivelmente mais eficiente em selecionar ou favorecer microorganismos ruminais com alta capacidade em metabolizar as liganans vegetais a enteroliganans do que o amido (BRITO et al., 2015).

Dando continuidade ao estudo de Brito et al. (2015), um subsequente estudo realizado pela mesma equipe de pesquisadores, avaliou o efeito da inclusão de níveis crescentes de melaço líquido sobre a concentração de EL no leite de vacas Jersey alimentadas com dietas a base de farelo de linhaça. $O$ farelo de milho foi substituído por quantidades crescentes de melaço líquido a $0,4,8$ ou $12 \%$ na MS da dieta. A concentração de EL no leite respondeu de forma cúbica aos níveis crescentes de melaço na dieta e concluiu-se que mais estudos são necessários para compreender como o metabolismo de SDG é afetado por açúcares dietéticos (GHEDINI et al., 2018a).

Considerando que, dentre as bactérias ruminais a Prevotella $s p$. provavelmente exerce papel importante no metabolismo ruminal de lignanas, alterações na dieta de vacas leiteiras que resultem em uma maior prevalência da Prevotella spp. no rúmen podem maximizar o metabolismo das lignanas contribuindo para um aumento na concentração de EL no leite. A inclusão de 4\% de óleo de linhaça na dieta de touros $(\% \mathrm{MS})$ resultou em uma maior prevalência do gênero Prevotella no rúmen em estudo realizado por Li et al. (2015). Apesar destes resultados, o efeito de ácidos graxos poliinsaturados sobre o metabolismo de SDG e subsequente concentração de EL no leite de vacas leiteiras não foi investigado até a presente data.

Estudos também tem sido conduzido no sentido de elucidar fatores como o tempo necessário de suplementação com lignanas vegetais para obter aumento na concentração de EL no leite bovino (GAGNON et al. 2009b) e estudar a biodisponibilidade da EL presente no leite bovino em animais mamíferos (GHEDINI et al., 2018b). Estes estudos serão brevemente apresentados a seguir.

Gagnon et al. (2009b) avaliaram o período de tempo para obter o pico de concentração de EL no leite de vacas alimentadas com $20 \%$ farelo de linhaça e o tempo de retorno ao nível basal de concentração de enterolactona quando as vacas são trocadas de alta para baixa ingestão de SDG proveniente da linhaça. Doze vacas Holandesas foram 
utilizadas neste estudo e inicialmente divididas em dois grupos experimentais, 1 e 2 . O grupo 1 recebeu dieta sem farelo de linhaça (dieta controle) durante todo o período do experimento (6 semanas no total). Enquanto que, o grupo 2 recebeu dieta com farelo de linhaça $(20 \%$ na MS) durante as três primeiras semanas do experimento e, a dieta controle durante as três últimas semanas. Os pesquisadores observaram interação significativa entre o regime de alimentação (controle e farelo de linhaça) e semana para a concentração de EL no leite, como resultado de maior concentração de EL da semana 1 a 3 para vacas no regime farelo de linhaça comparadas com as do regime controle (Figura 5).

Adicionalmente, este estudo sugere que a conversão de SDG a EL e a transferência de EL para a glândula mamária estão bem estabelecidas após uma semana de alimentação com $20 \%$ de farelo de linhaça na dieta, e o nível basal de EL no leite é atingido após uma semana de privação ao farelo de linhaça.

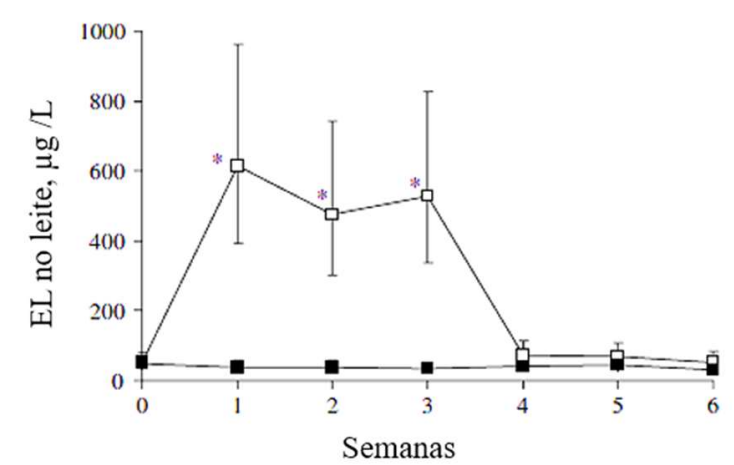

Figura 5. Concentrações de enterolactona (EL) no leite de vacas de leiteiras alimentadas com $20 \%$ farelo de linhaça na MS e a dieta controle.

Figure 5. Enterolactone (EL) concentrations in the milk of dairy cows fed $20 \%$ flaxseed meal in DM and the control diet.

Ghedini et al. (2018b) conduziram um estudo para determinar a farmacocinética da EL em bezerros recémnascidos alimentados com sucedâneo do leite (tratamento controle) ou leite bovino enriquecido com EL. Em bezerros recém-nascidos, a sucção estimula o fechamento do sulco esofágico para que o leite ou substituto do leite contornem o retículo-rúmen e cheguem até o abomaso. Assim, os bezerros podem ser usados como modelo para fazer inferências sobre a farmacocinética da EL presente no leite bovino em mamíferos de estômago simples, incluindo humanos. Vinte bezerros foram utilizados desde o nascimento até o dia 7 de vida. Todos os bezerros receberam colostro ao nascimento. A partir do fornecimento de colostro, os bezerros receberam $4 \mathrm{~L}$ de sucedâneo do leite por dia em duas alimentações diárias (as 7 da manhã e 7 da noite). No quinto dia de vida, os bezerros receberam $2 \mathrm{~L}$ de substituto do leite $(\mathrm{n}=10$; tratamento controle EL: $123 \mathrm{nmol} / \mathrm{L} \mathrm{EL}$ ) ou $2 \mathrm{~L}$ de leite enriquecido com EL ( $\mathrm{n}=10$; tratamento EL alto: $481 \mathrm{nmol}$ / L EL) durante a alimentação da manhã (0700 h). O leite enriquecido com EL era proveniente de uma vaca da raça Jersey alimentada com $20 \%$ de farelo de linhaça. Amostras de sangue foram retiradas da veia jugular antes $(0 \mathrm{~h})$ e a $0,5,1$, $1,5,2,2,5,3,4,6,8,10,12,24$ e 48 horas após a administração oral dos tratamentos. A concentração de EL no plasma dos bezerros está representada na Figura 9. Este estudo demonstrou que os bezerros foram capazes de absorver a EL do leite, indicando que o leite bovino enriquecido com EL pode ser potencialmente usado como fonte de EL para ruminantes pré-desmamados e possivelmente para humanos (Figura 6).

Existe atualmente grande interesse em maximizar o conteúdo de lignanas na dieta humana devido aos potenciais benefícios das enterolignanas, EL e ED a saúde humana. A produção de leite com elevada concentração de EL pode ser uma alternativa viável para o fornecimento de EL na dieta de humanos. Estudos avaliando como alterações na dieta de vacas leiteiras podem modular o metabolismo de lignanas no rúmen e subsequentemente as concentrações de EL no leite devem ser continuamente conduzidas para uma melhor elucidação das estratégias a serem adotadas no processo de aumento da concentração de EL no leite. Além disso, estudos avaliando o efeito benéfico a saúde humana do consumo de leite bovino com elevado teor de EL precisa ainda ser desenvolvidos.

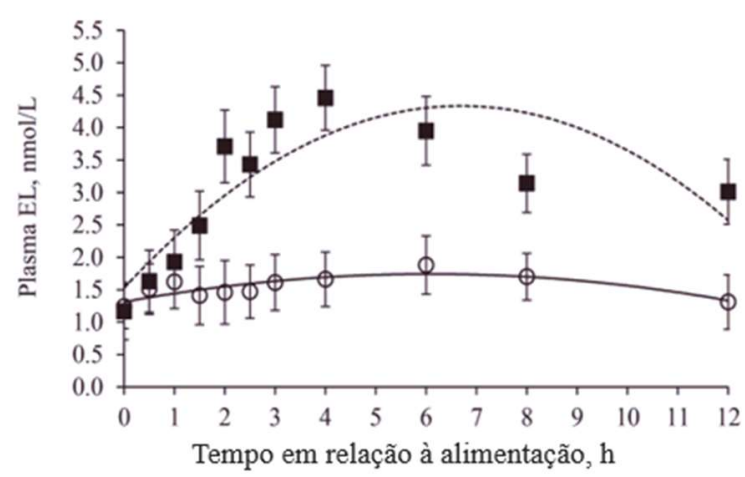

Figura 6. Concentração de enterolactona (EL) no plasma após a administração oral de $2 \mathrm{~L}$ de sucedâneo do leite (baixa concentração de EL; o) ou 2 L de leite com alta concentração de EL (alta concentração de EL; ש) para bezerros neonatos com $5 \mathrm{~d}$ de idade. Valores são média \pm desvio padrão.

Figure 6. Plasma enterolactone (EL) concentration after oral administration of $2 \mathrm{~L}$ of milk replacer (low EL concentration; $\mathrm{O}$ ) or 2 L of milk with high EL concentration (high EL concentration; $\mathbf{\square})$ to calves neonates with $5 \mathrm{~d}$ of age. Values are mean \pm standard deviation

\subsubsection{Aumento na concentração de Ácido Linoleico Conjugado (CLA) \\ O termo CLA descreve a família de isômeros geométricos} do ácido linoléico com propriedades bioativas distintas, que têm duas duplas ligações separadas por apenas uma ligação simples (insaturação conjugada). A conjugação da dupla ligação é geralmente nas posições 9 e 11 ou 10 e 12 (IP et al. 1994; ABU-GHAZALEH et al., 2001), porém existem outros isômeros presentes nos produtos de ruminantes. A configuração geométrica consiste nas formas cis-cis, cistrans, trans-cis e trans-trans (ABU-GHAZALEH et al., 2001). Em torno de 80 a 90\% do CLA presente nos produtos lácteos está presente na forma de isômeros cis-9, trans-11 (C18:2), sendo as formas biologicamente mais ativas de CLA (JENSEN, 2002; CRUMB, 2011).

Kepler e Tove (1971), descobriram que o primeiro intermediário na bio-hidrogenação do ácido linoleico pelas bactérias ruminais Butyrivibrio fibrisolvens, é o C18:2 cis-9, trans-11, o que sugere que os ruminantes podem converter $\mathrm{O}$ ácido linoleico em CLA explicando maior concentração de CLA em produtos de ruminantes. 
O primeiro grupo a relatar o efeito anticarcinogênico do CLA foi o grupo do Dr. Pariza's da Universidade de Wisconsin-Madison, nos Estados Unidos (Ha et al., 1987; Pariza; Hargraves, 1985).

Ha et al. (1987), utilizando técnicas de espectrofotometria e cromatografia, isolaram e caracterizaram estes componentes antimutagênicos desconhecidos da fração lipídica da carne. Os autores então, descobriram a existência de 4 isômeros derivados do ácido linoléico, sendo que cada um deles continha um sistema de dupla ligação conjugada, e, portanto, foram nomeados ácidos linoléicos conjugados (CLAs).

Em um estudo realizado por Pariza et al. (1979), observaram que a carne bovina grelhada tinha um componente carcinogênico, no entanto não conseguiram saber qual os quais componentes tinham. Hargreaves e Pariza (1983) continuaram seus estudos e observaram em extratos de carne a presença novamente de compostos com atividades antimutagênica e que são formadas durante o cozimento independentes do cozimento. Hargreaves e Pariza (1985) em estudos com camundongos observaram que estes componentes presentes nos estudos anteriores, foram capazes de inibir a progressão do tumor nas células epiteliais.

Os ruminantes fornecem a melhor fonte natural de CLA, para a dieta humana, provenientes da carne e do leite (CHIN et al., 1992). O CLA pode ser originado de duas vias sendo uma delas o rúmen, por meio da biohidrogenação incompleta de ácidos graxos poliinsaturados provenientes da dieta, e pela dessaturação do ácido graxo C18:1 trans-11 por ação da $\Delta$ dessaturase (CORL, 2001).

O metabolismo de lipídios no rúmen é iniciado pela hidrólise, que é realizada majoritariamente pelas bactérias. Posteriormente, os AG insaturados serão biohidrogenados. O primeiro passo da biohidrogenação é uma isomerização realizada por uma isomerase que converte o ácido graxo linoleico cis- 9 , cis-12 dieno metileno-interrompido em ácido cis-9, trans-11 (C18:2) dieno conjugado é um CLA (PALMQUIST; MATTOS, 2011). Este primeiro passo ocorre pela ação das bactérias ruminais dentre as bactérias a Butyrivibrio fibrosovens (MARTIN; JENKINS, 2002). Este metabólico intermediário, sendo rapidamente hidrogenado a trans 11 18:1 comumente chamado de ácido vacênico, e é liberado no ambiente ruminal. Os microrganismos secundários hidrogenam a ligação trans-11 com formação produto primário da biohidrogenação completa, o ácido esteárico 18:00 (Figura 10) (PALMQUIST; MATTOS, 2011).

A segunda fonte é o CLA sintetizado via endógena pela ação da enzima $\Delta$ 9-dessaturase na glândula mamária, que utiliza como substrato o ácido vacênico (trans-11 C18:1), que como descrito acima é um outro intermediário proveniente da biohidrogenação parcial dos ácidos graxos insaturados que ocorre no rúmen (Figura 7) (BAUMAN et al., 1999).
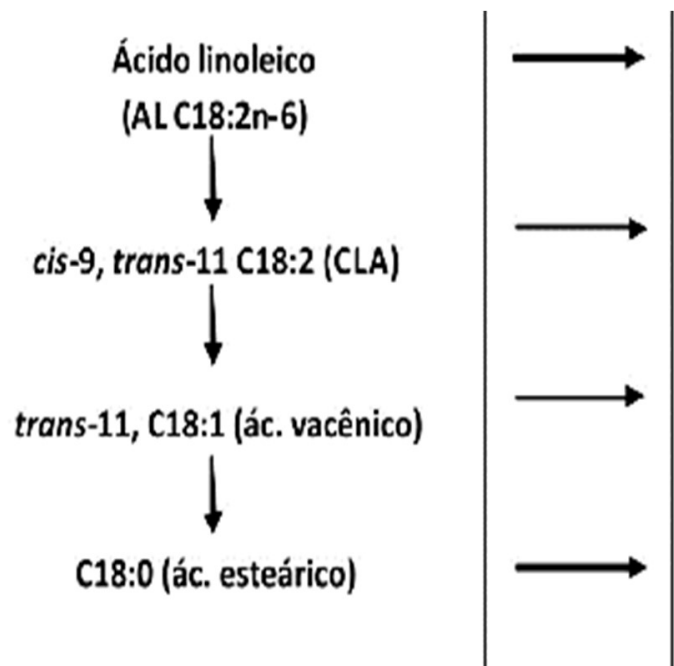

\section{Ácido linoleico \\ (ALC18:2n-6)}

cis-9, trans-11 C18:2 (CLA)

$\Delta 9$-Dessaturase

trans-11, C18:1 (ác. vacênico)

\section{C18:0 $\rightarrow$ cis-9 C18:1 (ác. oléico) \\ $\Delta 9$-Dessaturase}

Figura 7. a) Via metabólica de biossíntese do CLA no rúmen, b) Via metabólica de biossíntese do CLA no endógeno. Fonte: Adaptado de Bauman; Griinari (2001).

Figure 7. a) Metabolic pathway of CLA biosynthesis in the rumen, b) Metabolic pathway of CLA biosynthesis in the endogenous. Source: Adapted from Bauman; Griinari (2001).

A concentração e CLA na gordura do leite é muito variável, podendo ser atribuída a fatores relacionadas aos animais como raça, estágio de lactação, saúde e fatores relacionados à dieta como tipo de alimento, inclusão ácidos graxos insaturados na dieta, composição dos ácidos graxos e variação sazonal (JENSES, 2002; TSIPLAKOU et al., 2006).

Para que o CLA exerça seus efeitos benéficos sobre a saúde humana estima-se que a ingestão por pessoa seja 3 g.dia-1 (IP et al., 1991). Entretanto o consumo de CLA por brasileiros variam de $140 \mathrm{mg}$ a $1 \mathrm{~g} /$ dia dependendo da metodologia utilizada e dos hábitos alimentares da população (ANVISA, 2007).

A concentração de CLA no leite varia de 3 à $6 \mathrm{mg} / \mathrm{g}$ (KELLY et al., 1998). Em relação a concentração de CLA nos derivados lácteos (Tabela 2), a concentração de CLA é determinada nos derivados lácteos pela concentração inicial deste no leite empregado como matéria-prima ou devido ao enriquecimento do produto (LUCATTO et al., 2014).

O principal benefício do CLA é devido a alguns estudos indicarem que este exerce atividade anticarcinogênica, isso ocorre provavelmente por apresentar propriedades antiestrogênica (TANMAHASAMUT et al., 2004; HOLANDA et al., 2011).

Esta atividade faz com que o CLA atue, inibindo a síntese de nucleotídeo, reduzindo a atividade proliferativa de DNA do tumor, inibindo a ativação da carcinogênese (SCHULTZ et al., 1992; ZU; SCHUT, 1992; IP et al., 1994; PARODI, 1997; HOLANDA et al., 2011). O CLA também apresenta propriedades hipocolesterolêmica (KELLY; BAUMAN, 1996), e mecanismo antioxidante (BANNI et al., 1995). 
Tabela 2. Concentração de CLA em derivados lácteos

Table 2. Concentration of CLA in dairy products

\begin{tabular}{|c|c|c|}
\hline Investigador & $\begin{array}{c}\text { Derivado } \\
\text { lácteo }\end{array}$ & $\begin{array}{c}\text { Concentração média } \\
\text { de CLA/100 g }\end{array}$ \\
\hline \multirow{3}{*}{$\begin{array}{l}\text { Ledoux et al. (2005) } \\
\text { Serafeimidou et al. (2013). } \\
\text { El-Salam e El-Shibily } \\
(2014)\end{array}$} & Manteiga & 0,45 a 0,80 \\
\hline & Iogurte & 0,128 a 1,50 \\
\hline & Queijo & 0,05 a 2,50 \\
\hline
\end{tabular}

Fonte: adaptado de Lucatto el al. (2014).

Source: adapted from Lucatto el al. (2014).

O CLA também pode ser produzido sinteticamente contendo geralmente $40 \%$ de cis 9 , trans $11,40 \%$ de trans 10 , cis 12 e $20 \%$ de outros isômeros, estes CLA sintéticos estão disponíveis comercialmente vendido em alguns países (MCLEOD et al., 2004). Entretanto no Brasil para que o CLA sintético possa ser vendidos é necessário que as empresas apresentem documentação científica comprovando a segurança de uso e eficácia produtos uma vez que essas substâncias serão utilizadas em níveis superiores aos atualmente observados na alimentação da população brasileira. Esta preocupação é devido ao fato que em estudos com animais experimentais apresentaram efeitos adversos como aumento do fígado, esteatose hepática, hiperinsulinêmica e diminuição dos níveis séricos de leptina (ANVISA, 2007).

Como já descrito nesta revisão, vários são os fatores que influenciam na concentração de CLA na gordura do leite de ruminantes. Entretanto Griinari; Bauman (1999) descrevem que a dieta é o fator mais influente que determina a concentração de CLA.

Assim diante destes podemos melhorar a concentração de CLA alterando a alimentação de animais ruminantes em lactação. Concentrações maiores de CLA foram observadas no leite de animais alimentados com pasto em relação com dietas com ração (Tabela 3). No entanto Lock; Garnsworthy (2003) acreditam que parte do aumento pode ser devido ao aparente aumento da atividade de $\Delta$-dessaturase na glândula mamária de vacas alimentadas a pasto.

Tabela 3. Estratégias de suplementação para aumentar CLA da dieta.

Table 3. Supplementation strategies to increase dietary CLA.

\begin{tabular}{|c|c|c|c|}
\hline Investigador & Tratamento & $\begin{array}{l}\text { Concentração média de } \\
\text { CLA/ } 100 \mathrm{~g}\end{array}$ & Efeito \\
\hline \multirow{3}{*}{ Santos et al. (2001) } & Controle & 0,21 & \multirow{3}{*}{$\begin{array}{l}\text { Soja integral diminui o } \\
\text { óleo de soja aumentou }\end{array}$} \\
\hline & Soja integral & 0,18 & \\
\hline & Óleo de soja & 0,43 & \\
\hline \multirow[b]{2}{*}{ Kay et al. (2005) } & TMR (Controle) & 0,71 & \multirow[b]{2}{*}{ Pasto aumentou } \\
\hline & Pasto & 1,84 & \\
\hline \multirow{4}{*}{ Maia et al. (2006) } & Controle; & 0,91 & Aumentou; \\
\hline & $5,1 \%$ óleo de arroz; & 1,43 & Aumentou; \\
\hline & $5,1 \%$ óleo de canola; & 1,10 & Aumentou; \\
\hline & $5,1 \%$ óleo de soja & 1,70 & Sem efeito entre os óleos \\
\hline \multirow{2}{*}{$\begin{array}{l}\text { Bharathan et al. } \\
\text { (2008) }\end{array}$} & DDGS & 1,68 & Aumentou \\
\hline & Óleo de peixe & 2,24 & Aumentou \\
\hline \multirow{3}{*}{ Renna et al. (2010) } & Cevada de milho & 1,49 & \multirow{3}{*}{ Sem efeito } \\
\hline & $\mathrm{X}$ & & \\
\hline & Polpa de beteraba & 1,40 & \\
\hline \multirow[b]{2}{*}{ Baars et al. (2011) } & Feno de pasto & 6,1 & \multirow{2}{*}{ Silagem Aumentou } \\
\hline & Silagem & 8,2 & \\
\hline \multirow{4}{*}{ Souza (2011) } & 0\% óleo de Girassol & 0,12 & \multirow{4}{*}{ Aumentou com a inclusão de óleo de girassol } \\
\hline & 1,5 \% óleo de Girassol & 1,57 & \\
\hline & 3,0 \% óleo de Girassol & 2,60 & \\
\hline & 4,5 \% óleo de Girassol & 3,16 & \\
\hline \multirow{4}{*}{$\begin{array}{l}\text { Mutsvangwa et al. } \\
\text { (2012) }\end{array}$} & Canola laminado seco & 0,84 & \multirow{4}{*}{$\begin{array}{l}\text { Canola lamido seco aumento em relação canola peletizado; } \\
\text { linhaça peletizado aumento em relação linhaça laminado } \\
\text { seco. Linhaça aumento mais que a canola a concentração de } \\
\text { CLA. }\end{array}$} \\
\hline & Canola peletizado & 0,79 & \\
\hline & Linhaça laminado seco & 0,97 & \\
\hline & Linhaça peletizado & 1,83 & \\
\hline \multirow{3}{*}{$\begin{array}{l}\text { Kurokawa et al. } \\
\qquad(2013)\end{array}$} & $0 \%$ DDGS & 0,48 & \multirow{3}{*}{ Aumentou com a inclusão de DDGS na MS da dieta. } \\
\hline & $10 \%$ DDGS; & 0,78 & \\
\hline & $20 \%$ DDGS & 1,42 & \\
\hline \multirow{2}{*}{ Lahlou et al. (2014) } & TMR (Controle) & 0,71 & \multirow{2}{*}{ Pasto Aumentou } \\
\hline & Pasto & 1,06 & \\
\hline \multirow{4}{*}{$\begin{array}{l}\text { Ribeiro et al. } \\
\text { (2014) }\end{array}$} & $0 \%$ óleo de Girassol & 0,92 & \multirow{4}{*}{ Aumentou com a inclusão de óleo de girassol } \\
\hline & $1,3 \%$ óleo de Girassol & 1,28 & \\
\hline & $2,5 \%$ óleo de Girassol & 1,68 & \\
\hline & 3,7 \% óleo de Girassol & 2,21 & \\
\hline \multirow{7}{*}{$\begin{array}{l}\text { Gastelen et al. } \\
\text { (2015) }\end{array}$} & & 0,38 & \multirow{7}{*}{$\begin{array}{c}\text { A silagem de milho } 100 \% \text { aumentou as concentrações de } \\
\text { CLA. }\end{array}$} \\
\hline & (GS) $100 \%$ (100\% (Silagem capim); & & \\
\hline & (GS) $67 \%$ (67\% Silagem de & 0,35 & \\
\hline & $\begin{array}{l}\text { capim }+33 \% \text { silagem de milho); } \\
\text { (GS) } 33 \%(33 \% \text { Silagem de }\end{array}$ & & \\
\hline & capim $+67 \%$ Silagem de Milho; & 0,37 & \\
\hline & (GS) $0 \%(100 \%$ Silagem de milho $)$ & & \\
\hline & & 0,64 & \\
\hline \multirow{4}{*}{ Ceretti et al. (2016) } & $0 \%$ amendoim; & 2,24 & \\
\hline & $33 \%$ amendoim; & 1,15 & As concentrações de CLA diminuíram com a inclusão do \\
\hline & $66 \%$ amendoim; & 0,91 & amendoim \\
\hline & $100 \%$ amendoim & 1,14 & \\
\hline & Milheto & 11,63 & \\
\hline Bainbridge et al. & $\mathrm{X}$ & & Pastagem aumentou \\
\hline & Pastagem & 16,00 & \\
\hline
\end{tabular}

Fonte: elaborada pelos autores. Source: prepared by the authors. 
Estratégias com a inclusão de óleo ou sementes podem também aumentar as concentrações de CLA no leite. Observa-se também que os grãos de oleaginosas em comparação ao óleo contendo AG poli-insaturados, os óleos apresentaram maior concentração de CLA. Os grãos de oleaginosas terá um menor efeito na fermentação, isso provavelmente ocorre devido á lenta liberação do óleo presente no grão no fluido ruminal (NRC, 2001).

A formação de intermediários da biohidrogenação ruminal e do CLA é dependente da quantidade de ácido linoleico dietético (BAUMAN et al., 1999). Pesquisas posteriores, demostraram que as extensões da biohidrogenação ruminal aumentam com o acréscimo de ácidos graxos insaturados na dieta (DUCKETT et al., 2002). Assim, estudos com diferentes ingredientes nas dietas de animais ruminantes vêm sendo sendo realizados na tentativa de manipulação da biohidrogenação ruminal e consequentemente o aumento de CLA no leite (Tabela 3).

\section{CONSIDERAÇÕES FINAIS}

O leite é considerado um alimento completo por possuir a maior parte dos nutrientes essenciais. Além dos componentes tradicionais, pesquisas tem demonstrado que o leite é uma ótima fonte de biopeptideos e outros compostos bioativos que são necessários para a manutenção do organismo e para a prevenção de doenças. A inclusão de alimentos funcionais como a linhaça na alimentação de vacas leiteiras aumentou a concentração de enterolactona no leite. A inclusão de óleos vegetais, grãos e pastagem proporcionaram maiores concentrações de CLA. O aumento das concentrações de EL e CLA no leite aumenta o potencial nutracêutico do leite, portanto melhorando o potencial benéfico do leite a saúde humana.

Portanto, a produção a partir de precursores presentes nos alimentos e subsequente transferência de ambos, EL e CLA para o leite pode ser modulada por alterações na dieta das vacas leiteiras que possibilitam alterações no metabolismo ruminal e na síntese destes componentes nutracêuticos.

\section{REFERÊNCIAS}

ABU-GHAZALEH A. A.; SCHINGOETHE D. J.; HIPPEN A. R. Conjugated linoleic acid and other beneficial fatty acids in milk fatty from cows fed soybean meal, fish meal, or both. Journal of Dairy Science, v. 84 p. 1845-1850, 2001. DOI: https://doi.org/10.3168/jds.S0022-0302 (01)74624-3.

ADLERCREUTZ, H.; MAZUR, W. Phyto-oestrogens and Western diseases. Annals of Internal Medicine, v. 29, p. 95-120, $1997 . \quad$ DOI: https://doi.org/10.3109/07853899709113696

ANVISA. Esclarecimentos sobre as avaliações de segurança e eficácia do Ácido Linoléico Conjugado - CLA. 2007. Disponível

em: http://www.anvisa.gov.br/alimentos/informes/23_190 407.htm. Acesso em: 02/08/2020.

BAARS, T.; WOHLERS, J.; KUSCHE, D.; JAHREIS, G. Experimental improvement of cowmilk fatty acid composition in organic winter diets. Journal of Science of Food and Agriculture, v. 92, p. 2883-2890, 2012. DOI: https://doi.org/10.1002/jsfa.5525
BAILEY, A. E. Bailey's Industrial oil and fat products. 5 ed. New York: John Wiley, v. 3, 1996. 614p. DOI: https://doi.org/ 10.1002 / 047167849X.

BAINBRIDGE, M. L.; EGOLF, E.; BARLOW, J. W.; ALVEZ, J. P.; ROMAN, J.; KRAFT, J. Milk from cows grazing on cool-season pastures provides an enhanced profile of bioactive fatty acids compared to those grazed on a monoculture of pearl millet. Food Chemistry, v. 217, p. 750-755, 2017. DOI: $10.1016 /$ j.foodchem.2016.08.134

BHARATHAN, M.; SCHINGOETHE, D. J.; HIPPEN, A. R.; KALSCHEUR, K. F.; GIBSON, M. L.; KARGES, K. Conjugated linoleic acid increases in milk from cows fed condensed corn distillers solubles and fish oil. Journal of Dairy Science, v. 91 n. 7, p. 2796-2807, 2008. DOI: 10.3168/jds.2007-0938

BANNI, S.; DAY, B. W.; EVANS, R.W.; FRANCESCO P. C.; LOMBARDI, B. Detection of conjugated diene isomers of linoleic acid in liver lipids of rats fed a cholinedevoid diet indicates that the diet does not cause lipoperoxidation. Journal Nutrition Biochemistry, v. 6, p. 281-289, 1995. DOI: https://doi.org/10.1016/09552863(95)00049-6.

BAUMAN, D. E., BAUMGARD, L. H., CORL, B. A., GRIINARI, J. M. Biosynthesis of conjugated linoleic acid in ruminants. Proceeding of the American Society of Animal Science, 1999. 15p. Disponível em: https://www.agrireseau.net/bovinsboucherie/documen ts/CLA.pdf. Accesso em: 09 Nov. 202.

BAUMAN, D. E.; GRIINARI, J. M. Regulation and nutritional manipulation of milk fat: low-fat milk syndrome. Livestock Production Science, v. 70, n. 1-2, p. 15-29, 2001. DOI: https://doi.org/10.1016/S03016226(01)00195-6

BRITO, A. F.; PETIT, H. V.; PEREIRA, A. B.; SODER, K. J.; ROSS, S. Interactions of corn meal or molasses with a soybean-sunflower meal mix or flaxseed meal on production, milk fatty acid composition, and nutrient utilization in dairy cows fed grass hay-based diets. Journal of Dairy Science, v. 98, p. 443-457, 2015. DOI: https://doi.org/10.3168/jds.2014-8353.

CAPUANO, E.; RADEMAKER, J.; BIJGAART, V. D.; RUTH, S. M. Verification of fresh grass feeding, pasture grazing and organic farming by FTIR spectroscopy analysis of bovine milk. Food Research International, v. $60, \quad$ p. 59-65, 2014. DOI: https://doi.org/10.1016/j.foodres.2013.12.024

CHIN, S. F.; LIU, W.; STORKSON, J.M.; HA, Y.L.; PARIZA, M.W. Dietary sources of conjugated dienoic isomers of linoleic acid, a newly recognized class of anticarcinogens. Livestock Production Science, v. 5, p. 185-197, 1992. DOI: https://doi.org/10.1016/08891575(92)90037-K.

CHOWDHURY, R.; WARNAKULA, S.; KUNUTSOR, S.; CROWE, F.; WARD, H. A.; JOHNSON, L.; FRANCO, O. H.; BUTTERWORTH, A. S.; FOROUHI, N. G.; THOMPSON, S.G.; KHAW, K. T.; MOZAFFARIAN, D.; DANESH, J.; ANGELANTONIO, E. D. Association of dietary, circulating, and supplement fatty acids with coronary risk: a systematic review and metaanalysis. Annals of Internal Medicine, v. 160, n. 6, p. 398-406, 2014. DOI: 10.7326/M13-1788 
CLAVEL, T.; BORRMANN, D.; BRAUNE, A.; DORÉ, J.; BLAUT, M. Occurence and activity of human intestinal bacteria involved in the conversion of dietary lignans. Anaerobe, v. 12, p. 140-147, 2006. DOI: https://doi.org/10.1016/j.anaerobe.2005.11.002.

CÔRTES, C.; GAGNON, N.; BENCHAAR, C.; DA SILVA, D.; SANTOS, G.T.; PETIT, H.V. In vitro metabolism of flax lignans by ruminal and faecal microbiota of dairy cows. Journal of Applied Microbiology, v. 105, p. 1585-1594, 2008. DOI: https://doi.org/10.1111/j.1365-2672.2008.03922.x.

COZZOLINO, S. Nutracêuticos: o que significa?. 2012. Disponível

http://www.abeso.org.br/pdf/revista55/artigo.pdf. Acesso em: 03 ago. 2020.

CRUMB, D. J. Conjugated linoleic acid (CLA)-An Overview Int. International Journal of Applied Research in Natural Products, v. 4, p. 12-18, 2011.

DENMAN, S. E.; MCSWEENEY, C. S.; CORL, B. A.; BAUMGARD, L. H.; DWYER, D.A. The role of delta9-desaturase in the production of cis-9, trans-11. Journal of Nutritional Biochemistry, v. 12, n. 11, p .622-630, 2001.

FAO. Food and Agriculture Organization. Milk and dairy products in human nutrition. Rome; 2013. 404p. DOI: https://www.fao.org/3/i3396e/i3396e.pdf

FORD, J. D.; HUANG, K. S.; WANG, H. B.; DAVIN, L. B.; LEWIS, N. G. Biosynthetic pathway to the cancer chemopreventive secoisolariciresinoldiglucosidehydroxymethyl glutaryl ester-linked lignan oligomers in flax (Linum usitatissimum) seed. Journal of Natural Products, v. 64, p. 1388-1397, 2001. DOI: https://doi.org/10.1021/np010367x

FRANDSON, W. L.; FAIL, A. D. Anatomia e Fisiologia dos Animais de Fazenda. 7 ed. São Paulo: Guanabara Koogan, 2011. p. 359-365.

GAGNON, N.; CÔRTES, C.; PETIT, H V. Weekly excretion of the mammalian lignan enterolactone in milk of dairy cows fed flaxseed meal. Journal of Dairy Research, v. 76, p. 455-458, 2009. DOI: https://doi.org/10.1017/S0022029909990082

GAGNON, N.; CÔRTES, C.; SILVA, D.; KAZAMA, R.; BENCHAAR, C.; SANTOS, G. T.; ZEOULA, L. M.; PETIT, H. V. Ruminal metabolism of flaxseed (Linum usitatissimum) lignans to the mammalian lignan enterolactone and its concentration in ruminal fluid, plasma, urine and milk of dairy cows. British Journal of Nutrition, v. 102, p. 1015-1023, 2009. DOI: https://doi.org/10.1017/S0007114509344104

GASTELEN, S.V.; ANTUNES-FERNANDES, E. C.; HETTINGA, K. A.; KLOP, G.; ALFERINK, S. J.; DIJKSTRA, J. Enteric methane production, rumen volatile fatty acid concentrations, and milk fatty acid composition in lactating Holstein-Friesian cows fed grass silage- or corn silage-based diets. Journal of Dairy Science, v. $98, \quad$ n. 3, p. 1-13, 2015. DOI: https://doi.org/10.3168/jds.2014-8552

GERMAN, J. B.; GIBSON, R. A.; KRAUSS, R. M.; NESTEL, P.; LAMARCHE, B.; VAN STAVEREN, W.M.; STEIJNS, J.M.; DE GROOT, L. C.; LOCK, A. L.; DESTAILLATS, F. A reappraisal of the impact of dairy foods and milk fat on cardiovascular disease risk. European Journal of Nutrition, v. 48, n. 4, p. 191-203, 2009. DOI: $10.1007 /$ s00394-009-0002-5
GHEDINI, C. P.; BRITO, A. F.; REIS, S. F.; MOURA, D. C; OLIVEIRA, A. S.; SANTANA, R. A. V.; PEREIRA, A. B. D. Liquid Molasses Decreases Production Linearly and Changes Enterolactone Concentrations as a Corn Meal Substitute in Organic Dairy Cows Fed Flaxseed Meal. In: Organic Agriculture Research Symposium Pacific Grove, CA. Proceedings... January 20, 2016. 8p. Disponível em: https://www.eorganic.info/sites/eorganic.info/files/u2 7/4.6-Ghedini\&al-2016-Replacing_Corn_MealOARS_Proceedings-Final.pdf

GOMES, A. M.; PINTADO, M. E.; MALCATA, X. Conhecer a importância do leite na nutrição humana. Leite + I + D + T, Porto, v. 2, n. 7, p. 2-4, 2008.

GRIINARI, J. M.; BAUMAN, D. E. Biosynthesis of conjugated linoleic acid and its incorporation into meat and milk in ruminants. In: YURAWECZ, M. P.; MOSSOBA, M. M.; KRAMER, J. K. G.; PARIZA, M. W.; NELSON, G. J. (Eds.) Advances in Conjugated Linoleic Acid Research. Champaign, IL: AOCS Press, v. 1, 1999. p.180-200.

HA, Y. L.; GRIMM, N. K.; PARIZA, M. Anticarcionogens from fried ground beef: heat-altered derivatives of linoleic acid. Carcinogenesis, v. 8, n. 9, p. 1881-1887, 1987.

HARGREAVES, W. A.; PARIZA, M. W. Purification and mass spectral characterization of bacterial mutagens from commercial beef extract. Cancer Research, v. 43, n. 4, p. 1467-1472, 1983.

HOLANDA, M. A. C.; HOLANDA, M. C. R.; JUNIOR, A. F. M. Suplementação dietética de lipídios na concentração de ácido linoléico conjugado na gordura do leite. Acta Veterinária Brasílica, v. 5, n. 3, p. 221-229, 2011.

HOMAN, P.; WATTIAUX, M. A. Milk and milking. In: Guia Técnico da Pecuária Leiteira. Madinson, EUA: Inst. Babcok, 1996. 128p.

HUTH, P. J.; PARK, K. M. Influence of dairy product and milk fat consumption on cardiovascular disease risk: a review of the evidence. Advances in Nutrition, v. 3, p. 266-285, 2012. DOI: 10.3945/an.112.002030

IP, C.; SINGH, M.; THOMPASON, H. J.; SCIMECA, J. A. Conjugated linoleic acid suppresses mammary carcinogenesis and proliferative activity of the mammary gland in the rat. Cancer Research, v. 54, p. 1212-1215, 1994.

JENSEN, R.G. The composition of bovine milk lipids: January 1995 to December 2000. Journal Dairy Science, v. 85 , n. 2., p. 295-350, 2002. DOI: $10.3168 /$ jds.S00220302(02)74079-4

JIN, J.; HATTORI, M. A new mammalian lignin precursor, asarinin. Food Chemistry, v. 124, p. 895-899, 2011. DOI: $10.1016 /$ j.foodchem.2010.07.015

KAY, J. K.; ROCHE, J.R.; KOLVER, E. S.; THOMSON, N. A.; BAUMGARD, L. H. Comparison between feeding systems (pasture and TMR) and the effect of vitamin E supplementation on plasma and milk fatty acid profiles in dairy cows. Journal of Dairy Research, v. 72, n. 3, p. 322-332, 2005.2 DOI: https://doi.org/10.1017/S002202990500094

KELLY, M. L.; BERRY, J. R.; DAWER D. A.; GRIINARI, J. M.; CHOUINARD, P. Y.; VAN AMBURGH, M. E.; BAUMAN, D. E. Dietary fatty acid sources affected conjugated linoleic acid concentrations in milk from 
lactating dairy cows. Journal Dairy Science, v. 80, p. 2104-2114, $1998 . \quad$ DOI: https://doi.org/10.1093/jn/128.5.881

KELLY, M. L.; BAUMAN, D. E. Conjugated linoleic acid: a potentanticarcinogen found in milk fat. IN: Cornell Nutrition Conference, 58. Proceedings... Ithaca NY, p.6 8-74, 1996.

KEPLER, C. R.; HIRONS, K. P.; McNEILL, J.; TOVE, S. Intermediates and products of the biohydrogenation of linoleic acid by Butyrivibrio fibrisolvens. Journal of Biological Chemistry, v. 241, n. 6, p. 1350-1354, 1966.

KRATZ, M.; BAARS, T.; GUYENET, S. The relationship between high-fat dairy consumption and obesity, cardiovascular, and metabolic disease. European Journal of Nutrition, v.52, n.1, p.1-24, 2013 DOI: $10.1007 / \mathrm{s} 00394-012-0418-1$

KUROKAWA, Y.; SHIBATA, H.; TATENO, S.; KANDA, S.; TAKAURA, K.; ISHIDA, S.; ITABASHI, H. Rumen fermentation, milk production and conjugated linoleic acid in the milk of cows fed high fiber diets added with dried distillers grains with soluble. Animal Science Journal, v. 84, p. 106-112, 2013. DOI: 10.1111/j.17400929.2012. 01052.x

LAHLOU, M. N.; KANNEGANTI, R.; MASSINGILL, L. J.; BRODERICK, G. A.; PARK, Y.; PARIZA, M. W.; FERGUSON, J.D.; WU, Z. Grazing increases the concentration of CLA in dairy cow milk. Animal, v. 8, n. 7, n. 7, p. 1191-1200, 2014. DOI: https://doi.org/10.1017/S1751731114000998

LANDETE, J. M. Plant and mammalian lignans: a review of source, intake metabolism, intestinal bacteria and health. Food Research International, v. 46, p. 410-424, 2012. DOI: https://doi.org/10.1016/j.foodres.2011.12.023

LIMA, L. S.; PALIN, M. F.; SANTOS, G. T.; BENCHAAR, C.; PETIT, H. V. Dietary flax meal and abomasal infusion of flax oil onmicrobial_-glucuronidase activity and concentration ofenterolactone in ruminal fluid, plasma, urine and milk of dairy cows. Animal Feed Science and Technology, v. 215, p. 85-91, 2016. DOI: 10.1016/j.anifeedsci.2016.03.006

LIU, Z.; SAARINEN, N. M.; THOMPSON, L. U. Sesamin is one of the major precursors of mammalian lignans in sesame seed (Sesamum indicum) as observed in vitro and in rats. The Journal of Nutrition, v. 136, p. 906-912, 2006. DOI: https://doi.org/10.1093/jn/136.4.906

LOCK, A. L.; GARNSWORTHY, P. C. Seasonal variation in milk newly recognized class of anticarcinogens. Journal of Food Composition and Analysis, v. 5, p. 185-197, 2003.

LUCATTO, J. N.; MENDONÇA, S. N. T. G.; DRUNKLER, D. A. Ácido linoleico conjugado: estrutura química, efeitos sobre a saúde humana e análise em lácteos. Revista do Instituto de Laticínios Cândido Tostes, v. 69, n. 3, p. 199-211, 2014.

MACHADO, F. M. S. Estratégias de concorrência da indústria alimentícia e seus desdobramentos na dimensão nutricional. 2003. 213f. Tese (Doutorado em Nutrição Humana Aplicada) - Faculdade de Ciências Farmacêuticas, Universidade de São Paulo, São Paulo, 2003.

MAIA, F. J.; BRANCO, A. F.; MOURO, G. F.; CONEGLIAN, S. M.; SANTOS, G. T.; MINELLA, T. F.; GUIMARÃES, K. C. Inclusão de fontes de óleo na dieta de cabras em lactação: produção, composição e perfil dos ácidos graxos do leite. Revista Brasileira de Zootecnia, v. 35, n. 4, p. 1504-1513, 2006.

MAISUTHISAKUL, P.; SUTTAJIT, M.; PONGSAWATMANIT, R. Assessment of phenolic content and free radical-scavenging capacity of some Thai indigenous plants. Food Chemistry, London, v. 100, n. 4, p. 1409-1418, $2007 . \quad$ DOI: https://doi.org/10.1016/j.foodchem.2005.11.032

MARTIN, S. A.; JENKINS, T. C. Factors affecting conjugated linoleic acid trans-C18:1 fatty acid production by mixed ruminal bacteria. Journal of Animal Science, v. 80, n. 12, p. 3347- 3352, 2002.

MARTINS, S.V.; LOPES, P. A.; ALFAIA, C. M.; RIBEIRO, V. S.; GUERREIRO, T. V.; FONTES, C. M. G. A.; CASTRO, M. F.; SOVERAL, G.; PRATES, J. A. M. Contents of conjugated linoleic acid isomers in ruminantderived foods and estimation of their contribution to daily intake in Portugal. British Journal of Nutrition, v. 98 , n. 6, p. 1206-1213, 2007. DOI: https://doi.org/10.1017/S0007114507781448

MASSEY, L. K. Dairy food consumption blood pressure and stroke. The Journal of Nutrition, v. 131, n. 7, p. 18751878, 2001. DOI: $10.1093 /$ jn/131.7.1875

MCLEOD, R. S.; LEBLANC, A. M.; LANGILLE, M. A.; MITCHELL, P. L.; CURRIE, D. L. Conjugated linoleic acids, atherosclerosis, and hepatic very-low-density lipoprotein metabolism. American Journal of Clinical Nutrition, v. 79, p. 1169S-74S, 2004. DOI: $10.1093 /$ ajcn/79.6.1169S

MICINSKIA, J.; KOWALSKI, I. M.; ZWIERZCHOWSKI, G.; SZAREK, J.; PIEROZYNSKI, B.; ZABLOCKA, E. Characteristics of cow's milk proteins including allergenic properties and methods for its reduction. Polish Annals of Medicine, v. 20, n. 1, p. 69-76, 2013. DOI: https://doi.org/10.1016/j.poamed.2013.07.006

MORAES, F. P.; COLLA, L. M. Alimentos funcionais e nutracêuticos: definições, legislação e benefícios à saúde. Revista Eletrônica de Farmácia, v. 3, n. 2, p.109-122, 2006.

MUNIZ, L. C.; MADRUGA, S. W.; ARAÚJO, C. L. Consumo de leite e derivados entre adultos e idosos no Sul do Brasil: um estudo de base populacional. Ciência e Saúde Coletiva, v. 18, n. 12, p. 315-3522, 2013. DOI: https://doi.org/10.1590/S1413-81232013001200008

MUTSVANGWA, T.; HOBIN, M.R.; GOZHO, G. N. Effects of method of barley grain processing and source of supplemental dietary fat on duodenal nutrient flows, milk fatty acid profiles, and microbial protein synthesis in dairy cows. Journal Dairy Science, v. 95, p. 5961-5977, 2012. DOI: $10.3168 /$ jds.2012-5491

NRC_National Research Council. Nutrient requeriments of dairy cattle. 1.ed. Washington, D.C.: National Academy, 2001. 405p.

ORDÓÑEZ, J. A.; RODRÍGUEZ, M. I. C.; ÁLVAREZ, L. F.; SANZ, M. L. G. MINGUILLÓN, G. D. G. F.; PERALES, L. H.; CORTECERO, M. D. S. Tecnologia de alimentos: alimentos de origem animal. Porto Alegre: Artmed, 2005. 280p.

PALMQUIST, D. L.; MATTOS, W. R. S. Metabolismo de lipídeos. In: BERCHIELI, T. T.; PIRES, A. V.; OLIVEIRA, S. G. (Eds.). Nutrição de ruminantes. 2 ed. Jaboticabal: Funep, 2011. p. 299-322.

PARIZA, M. W.; ASHOOR, S. H.; CHU, F.S.; LUND, D.B. Effects of temperature and time on mutagen formation 
in pan-fried hamburger. Cancer Letters, v. 7, n. 2-3, p. 63-69, 1979. DOI: https://doi.org/10.1016/S03043835(79) $80097-\mathrm{X}$

PARIZA, M. W.; HARGREAVES, W. A. A beef-derived mutagenesis modular inhibits initiation of mouse epidermal tumors by 7,12-dimethylbenz(a) anthracene. Carcinogenesis, v. 6, n. 3, p. 591-593, 1985. DOI: $10.1093 /$ carcin/6.4.591

PARODI, P.W. Cows' milk fat components as potential anticarcinogenic agent. Journal Nutrition, v. 127, n. 6, p. 1055-1060, 1997. DOI: 10.1093/jn/127.6.1055

PATTERSON, E.; LARSSON, S. C.; WOLK, A.; ÅKESSON, A. Association between dairy food consumption and risk of myocardial infarction in women differs by type of dairy food. The Journal of Nutrition, v. 143, n. 1, p. 74-9, 2013. DOI: 10.3945/jn.112.166330

PEREIRA, M. A.; JACOBS Jr, D. R.; VAN HORN, L.; SLATTERY, M. L. KARTASHOV, A. I.; LUDWIG, D. S. Dairy consumption, obesity, and the insulin resistance syndrome in young adults: the CARDIA study. JAMA, v. 287, n. 16, p. 2081-2089, 2002. DOI: $10.1001 /$ jama.287.16.2081

PETIT, H. V.; GAGNON, N. Concentration of the mammalian lignans enterolactone and enterodiol in milk of cows fed diets containing different concentrations of whole flaxseed. Animal, v. 3, p. 1428-1435, 2009. DOI: $10.1017 /$ S1751731109990346

PETIT, H. V.; GAGNON, N. Milk concentration of the mammalian lignans enterolactone and enterodiol, milk production, and whole tract digestibility of dairy cows fed diets containing different concentrations of flaxseed meal. Animal Feed Science and Technology, v.152, p.103111, 2009.

PETIT, H. V.; GAGNON, N. Production, performance and milk composition of dairy cows fed different concentrations of flax hulls. Animal Feed Science and Technology, v.169, p.46-52, 2011. DOI: 10.3168/jds.2006-573

PETIT, H. V.; GAGNON, N.; MIR, P. S.; CAO, R.; CUI, S. Milk concentration of the mammalian lignan enterolactone, milk production, milk fatty acid profile, and digestibility in dairy cows fed diets containing whole flaxseed or flaxseed meal. Journal of Dairy Research, v. 76, p. 257-264, 2009. DOI: 10.1017/S0022029909003999

PHILIPPI, S. T.; LATTERZA, A. R.; CRUZ, A. T. R.; RIBEIRO, L. C. Pirâmide alimentar adaptada: guia para escolha dos alimentos. Revista de Nutrição, Campinas, v. 12 , n. 1 , p. $65-80$, 1999. DOI: https://doi.org/10.1590/S1415-52731999000100006

RAFFAELLI, B.; HOIKKALA, A.; LEPPÄLÄ, E.; WÄHÄLÄ, K. Enterolignans. Journal of Chromatography B, v. 777, p. 29-43, 2002.

REECE, W. O. Fisiologia de animais domésticos. 1 ed. São Paulo: Edit. Roca, 1996. p. 313-325.

RENNA, M.; COLLOMB, M.; MUNGER, A.; WYSS, U. Influence of low-level supplementation of grazing dairy cows with cereals or sugar beet pulp on the concentrations of CLA isomers in milk. Journal of the Science of Food and Agriculture, v. 90, p.1256-1267, 2010. DOI: https://doi.org/10.1002/jsfa.3968

RIBEIRO, C. G.; LOPES, F. C. F.; GAMA, M. A. S.; MORENZ, M. J. F.; RODRIGUEZ, N. M. Desempenho produtivo e perfil de ácidos graxos do leite de vacas que receberam níveis crescentes de óleo de girassol em dietas à base de capim-elefante. Arquivo Brasileiro de Medicina Veterinária, v. 66, n. 5, p. 15131521, 2014. DOI: https://doi.org/10.1590/1678-6886

SAARINEN, N. M.; SMEDS, A.; MÄKELÄ, S. I.; ÄMMÄLÄ, J.; HAKALA, K.; PIHLAVA, J. M.; RYHÄNEN, E. L.; SJÖHOLM， R.; SANTTI，R. Structural determinants of plant lignans for the formation of enterolactone in vivo. Journal of Chromatography B, v. 777 , n. 1-2, p. 311-319, 2002. DOI: 10.1016/s15700232(02)00339-2

SAARINEN, N. M.; THOMPSON, L. U. Prolonged administration of secoisolariciresinol diglycoside increases lignan excretion and alters lignan tissuedistribution in adult male and female rats. British Journal of Nutrition, v. 104, p. 833-841, 2010. DOI: 10.1017/S0007114510001194

SANTOS, G. T.; SILVA-KAZAMA, D. C.; GRANZOTTO, F. Modulação da produção, composição e estabilidade oxidativa do leite. In: MARCONDES, M.I.; VELOSO, C.M.; GUIMARÃES, J. D. (Eds). III Simpósio Nacional de Bovinocultura Leiteira e I Simpósio Internacional de Bovinocultura Leiteira - SIMLEITE. Anais... ViçosaMG: Suprema Gráfica e Editora LTDA, 2011. p.151-174. SANTOS, F. L.; SILVA, M. T. C.; LANA, R. P.; BRANDÃO, S. C. C.; VARGAS, L. H.; ABREU, L.R. Efeito da Suplementação de Lipídios na Ração sobre a Produção de Ácido Linoléico Conjugado (CLA) e a Composição da Gordura do Leite de Vacas. Revista Brasileira de Zootecnia, v. 3, n. 6, p. 1931-1938, 2001.

SETCHELL, K. D. R.; LAWSON, A. M.; MITCHELL, F. L.; ADLERCREUTZ, H.; KIRK, D. N.; AXELSON, M. Lignans in man and in animal species. Nature, v. 287, p. 740-742, 1980.

SINGH, V. P.; SACHAN, N. Nutraceutical Properties of Milk and Milk Products: A Review. American Journal of Food Technology, v. 6, n. 10, p. 864-869, 2011. DOI: 10.3923/ajft.2011.864.869

SHULTZ, T. D.; CHEW, B. P.; SEAMAN, W. R.; LUEDECKE, L. O. Inhibitory effect of conjugated dienoic derivatives of linoleic acid and b-carotene on the in vitro growth ofhuman cancer cells. Cancer Lell, v. 63, n. 2, p. 125-133, 1992. DOI: $10.1016 / 0304-$ 3835(92)90062-z

SIMIC, M. G.; JAVANOVIC, S. V.; HO, C. T.; OSAWA, T.; HUANG, T. M.; ROSEN, R. T. Inactivation of oxygen radicals by dietary phenolic compounds in anticarcinogenesis. Food Phytochemicals for Cancer Prevention, n. 547, p. 20-32, 1994. DOI: 10.1002/chin.199415325

SOUZA, S. M. 2004. Desempenho e perfil de ácido graxos do leite de vacas alimentadas com óleo de girassol em dietas a base de cana-de-açúcar. $87 \mathrm{f}$. Tese (Doutorado em zootecnia) - Universidade Federal de Viçosa, Viçosa, 2004.

STOPPER, H.; SCHMITT, E.; KOBRAS, K. Genotoxicity of phytoestrogens. Mutation Research, v. 574, p. 139155, 2005. DOI: $10.1016 /$ j.mrfmmm.2005.01.029

TANMAHASAMUT, P.; LIU, J.; HENDRY, L. B.; SIDELL, N. Conjugated linoleic acid blocks estrogen signaling in human breast cancer cells. American Society for Nutritional Sciences, v. 22, n. 3, p. 3160- 3166, 2004. DOI: $10.1093 /$ jn/134.3.674

THOMPSON, L. Flaxseed, lignans and cancer. 2 ed. Champaign, IL, USA: AOCS Press, 2004. p.194-222. 
THOMPSON, L. U.; ROBB, P.; SERRAINO, M.; CHEUNG, F. Mammalian lignan production from various foods. Nutrition and Cancer, v. 16, p. 43-52, 1991. DOI: $10.1080 / 01635589109514139$

TOURE, A.; XU, X. M. Flaxseed lignans: source, biosynthesis, metabolism, antioxidant activity, bio-Active components, and health benefits. Comprehensive Reviews in Food Science and Food Safety, v. 9, p. 261-269, 2010. DOI: https://doi.org/10.1111/j.15414337.2009.00105.x

TOMBINI, H.; DALLACOSTA, M. C.; BLEIL, R. A. T.; ROMAN, J. A. Consumo de leite de vaca e derivados entre agricultores da região oeste do Paraná. Alimentos e Nutrição, v. 23, n. 2, p. 267-274, 2012.

TSIPLAKOU, E. MOUNTZOURIS, K. C.; ZERVAS, G. Concentration of conjugated linoleic acid in grazing sheep and goat milk fat. Livestock Science, v. 103, n. 12, p. 74-84, 2006. DOI: https:// doi.org/10.1016/j.livsci.2006.01.010

US Department of Agriculture (USDA) and US Department of Health and Human Services. Dietary Guidelines for Americans, 2010. 7th Edition, Washington, DC: U.S. Government Printing Office, December; 2010. Disponível em: http://health.gov/dietaryguidelines/2010/. Acesso em: 19/12/2020.

ZHOU, W.; WANG, G.; HAN, Z.; YAO, W.; ZHU, W. Metabolism of flaxseed lignans in the rumen and its impact on ruminal metabolism and flora. Animal Feed Science and Technology, v. 150, p. 18-26, 2009. DOI: 10.1016/j.anifeedsci.2008.07.006

ZU, I. L.-X.; SCHUT, I. L. A. J. Inibition of 2-amino-3methylimidzol 4,5-f quinoline-DNA adduct formation in CDF1 mice by heat-altered derivatives of linoleic acid. Food Chemical Toxicology, v. 30, p. 9-16, 1992. DOI: 10.1016/0278-6915(92)90131-4 